\title{
Determinant of Smoking Behavior among Elementary Student in Indonesia: A Structure Equation Model
}

\author{
Astrid Novita Haryanto ${ }^{1,5 *}$, Melinda Noer ${ }^{2}$, Agustin Kusumayati ${ }^{3}$, Rizanda Machmud ${ }^{4}$, Muhammad Hafizurrachman ${ }^{5}$, \\ Adang Bachtiar ${ }^{5}$ \\ ${ }^{1}$ Student of Doctoral Program of Public Health Sciences, Faculty of Medicine, Andalas University, West Sumatera, Indonesia; \\ ${ }^{2}$ Department of Socioeconomic Agriculture, Faculty of Agriculture, Andalas University, West Sumatera, Indonesia; ${ }^{3}$ Department \\ of Public Health Science, Faculty of Public Health, University of Indonesia, Depok, West Java, Indonesia; ${ }^{4}$ Department of \\ Nursing Science, Faculty of Nursing, Andalas University, West Sumatera, Indonesia; ${ }^{5}$ Department of Public Health, Indonesia \\ Maju School of Health Science, Jakarta, Indonesia
}

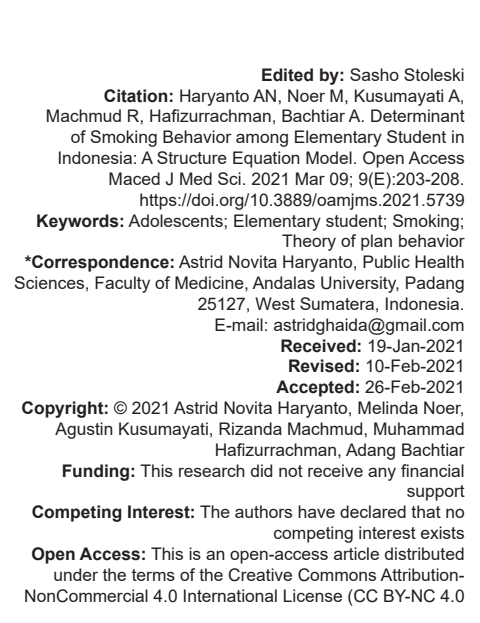

\section{Introduction}

Smoking is a leading cause of preventable death worldwide, responsible for 1 in 10 deaths worldwide [1]. Around 1.3 billion people worldwide smoke and 7 million people die from tobacco consumption every year [1]. Despite efforts to reduce smoking rates among adults, smoking rates among young people continue to increase. Indonesia is the third largest smoking country in the world (46.16\%) [2]. Tobacco smoking prevalence among students aged 10-14 years old was estimated to be $87.5 \%$ [2].

Adolescents are more prone to smoking if they were in a peer group that smokes [3]. The influence of the family on adolescent smoking is mainly due to the direct effects of family poverty, smoking parents, and family processes [4], [5]. Strong parental influence is demonstrated by the influence of parents, teachers, and siblings, while perceived social influence is shown by peers, parents, and siblings [3]. The stronger the family relationship, the more likely adolescent smoking is to be stopped and avoided [6]. Adolescents are less likely to engage in risky behavior, such as alcohol consumption, drug use, juvenile delinquency, and smoking, if they have parents who set a good example for their activities inside and outside the family [7]. In some societies, there are several customs about smoking. For example, in Aceh culture (Indonesia), smoking is a cultural custom of enjoyment [8].

The social determinants of smoking behavior were carried out using a number of theoretical frameworks [2], [9], [10], [11], [12]. The theory of planned behavior (TPB) has been used to test if smoking is a learned behavior, as well as develop interventions to reduce cigarette consumption [13]. TPB assumes that the best predictor of behavior is behavioral intention; intention, in turn, has three determinants including subjective norm, perceive benefit, and perceive behavior control [14]. Despite several factors impacting adolescent 
smoking behaviors, this study adds others variables to the TPB including smoking refusal skills, self-regulation, parenting, family function, environment, and culture. The objective of this study was to identify the most important factors associated with smoking behavior among elementary school students in Indonesia.

\section{Methods}

\section{Research design}

A cross-sectional survey was carried out from June to October 2019 in West Java, Indonesia. The study was able to determine the prevalence of all factors under investigation at one point in time. The study was carried out in the two largest districts of the city of Bogor, West Java, Indonesia. The list of schools was provided by the Ministry of Education. The schools were further stratified by form (private or public). The sample size was based on the assessment of the rootmean-square error of approximation (RMSEA). For each school, students were selected using a systematic random sampling technique.

\section{Inclusive and exclusive criteria}

The study included girls and boys ages 10-12. The consent was obtained by the parent or guardian. Children who were not in school during the data collection period were not included in the study. People who were mentally challenged and children whose parents or guardians declined to provide assent or could not give consent did not take part in the study.

\section{Instruments}

The research instrument was the selfadministered questionnaire which consisted of personal information, age, gender, family members' smoking status, friends' smoking status, age of the first use, and current smoking status. Students' current smoking was defined if smoking for $\geq 1$ day during the past 30 days.

The student's intentions were measured using seven items to assess their smoking intentions. It asked "During the next 3 months, do you think you will smoke a cigarette?" If your best friend offered you a cigarette, would you smoke it? "How likely do you think your answers are to the following?" (Very unlikely). The researcher built the questionnaires based on the elicitation results and used them to estimate the content validity. Content validity ratio was 0.78 and content validity index (CVI) was 0.82 . The internal consistency reliability coefficients was 0.69 .

Attitudes toward smoking were measured using four items from the Global Youth Tobacco Survey
(GYTS) such as "It makes you confident," "Cigarettes are enjoyable," "Positive attitudes toward non-smokers" such as "There are cool people who do not smoke" and "I think someone my age who does not smoke cigarettes looks well kempt." Content validity was reviewed and approved by 5 experts with CVI range from 0.80 to 0.84 . The internal consistency reliability coefficient was 0.72 .

Subjective norm was assessed using three GYTS-derived items to test the effect of adolescent referents (parents, guardians and friends) on their smoking activity. Participants with mothers/female guardians or caregivers who smoke, and students who perceive norms conformity with smoking were asked to answer the questions. These were scored on a 5-point Likert differential scale, with scores ranging from 1 (strongly agree) to 5 (strongly disagree). Content validity was reviewed and approved by 5 experts with $\mathrm{CVI}$ range from 0.80 to 0.84 . The internal consistency reliability coefficients was 0.72 .

Perceived behavioral control was assessed by the single item extracted from GYTS, the feeling or belief that they should reject a cigarette if a friend offers. A 5-point Likert differential scale from 1 (very difficult) to 5 (very easy for me) were used to score the perceived behavior control. Content validity was reviewed and approved by 5 experts with $\mathrm{CVI}$ range from 0.80 to 0.84 . The internal consistency reliability coefficients was 0.72 .

Parenting is divided into authoritarian, democratic, and permissive. These were scored on a 5-point Likert differential scale, with scores ranging from 1 (strongly agree) to 5 (strongly disagree). Content validity was reviewed and approved by 5 experts with $\mathrm{CVI}$ range from 0.75 to 0.78 . The internal consistency reliability coefficients was 0.70 .

The environment is defined in the areas of family modeling, socialization with peers, and the accessibility of smoking facilities. These were scored on a 5-point Likert differential scale, with scores ranging from 1 (strongly agree) to 5 (strongly disagree). Content validity was reviewed and approved by 5 experts with $\mathrm{CVI}$ range from 0.81 to 0.83 . The internal consistency reliability coefficients was 0.76 .

Culture is included in individualism, collectivism, and social system symbols as measured by the differential semantic scale. Content validity was reviewed and approved by 5 experts with $\mathrm{CVI}$ range from 0.75 to 0.80 . The internal consistency reliability coefficients was 0.70 .

Self-efficiency consists of three things, namely: Magnitude, generality, and strength. Magnitude refers to assessing a person's level of difficulty in performing a specific task (e.g., how difficult is my job?). Power is the sum of the confidence of a person in good performance at a varying degree of difficulty or ability to perform a specific task (e.g., how sure am I that I can succeed at the job?). Generality refers to the degree to which 
there are universal standards across circumstances (e.g., how to ensure that my new assignments apply to what I have learned?). For the self-efficacy component, the response varies from: (1) (Never able to do it), (2) (sometimes unable to do it), (3) (neutral), (4) (quite capable of doing it), (5) (quite capable of doing it), and (6) (always capable). Content validity was reviewed and approved by 5 experts with CVI range from 0.73 to 0.79 . The internal consistency reliability coefficient was 0.73 .

In this study, self-regulation is as follows: (1). Setting up standards/objectives, (2). Management of the strategy, and (3). Self-controlling. For self-regulation variables, the answer ranges are: (1) (Never does it), (2) (sometimes do it), (3) (neutral), (4) (ever), and (5) (never) (always). Content validity was reviewed and approved by 5 experts with CVI range from 0.77 to 0.82 . The internal consistency reliability coefficient was 0.77 .

\section{Smoking Refusal Skill}

Participants were asked to decide what they should do in a scenario where someone offered them a cigarette, with five choices available: "I certainly declined," "I say: I'm not smoking now," "I'm leaving the spot," "I'm not going to smoke," and "I'm going to change the topic of the conversation." Five answers were scored on a 5-point scale, ranging from 1 (strongly agreed) to 5-point (strongly disagree). Content validity was reviewed and approved by 5 experts with CVI range from 0.78 to 0.82 . Internal reliability of the data was checked at 0.75 .

\section{Procedure}

Ethical approval was obtained from the ethics research committee of the study institution. Information and name list regarding studied participants were obtained from the head of the school. All guardian or parental consent was sought. The researcher distributed a set of self-administered anonymous questionnaires to those who agreed to participate during the class break. Time to complete all questioners were around 25 to 45 minutes.

\section{Data analysis}

Assumptions for normality and homoscedasticity were met as the data were not skewed. Descriptive statistics (frequencies, percentages, mean, and standard deviation) and Pearson correlation statistical test was used to determine associations between outcome and exposure variables. Path analysis is used to determine those factors that influence smokers' behaviors. The fit of the model was examined by the non-significant Chisquare value, the RMSEA, standardized root means square residual (SRMR), non-normed fit index (NNFI), comparative fit index (CFI), and adjusted goodnessof-fit indices (AGFI). RMSEA and SRMR are below 0.08 , indicating an appropriate fit. The AGFI, CFI, and NNFI values ranged between 0 and 1 , with $A G F I$ and 0.90 and $\mathrm{CFI}$ and $\mathrm{NFI}$ and 0.97 , which indicate that they are well fitted to the data [15]. IBM SPSS version 25 (Chicago, IL) statistical software LISREL Version 8.8 (Scientific Software International, Inc., Skokie, IL, USA) was used for data entry and analysis, and the level of significance was set at $p<0.05$.

\section{Results}

\section{Demographic characteristics}

Table 1 shows the demographic characteristics of adolescent age of 10-12 years old in this study. The mean age was 10.56 years $(S D=0.37)$. About $28.6 \%$ of them were currently smoking, and their aged of first smoking was $10.02(S D=0.19)$. More than half $(56 \%)$ of their family were currently smoking too and friend smoking was $41.7 \%$.

Table 1: Demographic characteristics of studied participants $(n=175)$

\begin{tabular}{ll}
\hline Variables & $\mathrm{n}(\%)$ \\
\hline Age in year (mean \pm SD) & $10.56 \pm 0.37$ \\
Gender & \\
$\quad$ Male & $85(48.6)$ \\
$\quad$ Female & $90(51.4)$ \\
Current smoking & \\
$\quad$ Yes & $50(28.6)$ \\
$\quad$ No & $125(71.4)$ \\
Age of first use & $10.02 \pm 0.19$ \\
Family smoking & \\
Yes & $98(56.0)$ \\
$\quad$ No & $77(44.0)$ \\
Friend smoking & \\
$\quad$ Yes & $73(41.7)$ \\
No & $102(58.3)$ \\
\hline
\end{tabular}

Table 2 shows bivariate analysis of determinant factors of smoking behavior among adolescent aged 10-12 years old. Environment, culture, family function, skill to refuse, subjective norm, self-efficacy, selfregulation, attitude toward smoking, parenting, and intention were significant associated with smoking behavior with $r$ value ranged from 0.103 to 0.616

Table 2: Bivariate analysis of determinant factors for smoking behaviors among adolescent

\begin{tabular}{llll}
\hline Variables & Mean (SD) & Range & $\mathrm{r}$ \\
\hline Environment & $21.7 \pm 6.9$ & $6.0-30.0$ & $0.217^{* *}$ \\
Culture & $18.3 \pm 6.6$ & $7.0-30.0$ & $0.273^{*}$ \\
Family function & $119.7 \pm 18.9$ & $54.0-148.0$ & $0.141^{*}$ \\
Skill to refuse & $17.5 \pm 2.8$ & $2.0-27.0$ & $0.103^{*}$ \\
Subjective norm & $22.6 \pm 4.2$ & $10.0-30.0$ & $0.345^{\star *}$ \\
Self-efficacy & $24.6 \pm 5.9$ & $6.0-30.0$ & $0.191^{*}$ \\
Self-regulation & $24.7 \pm 3.8$ & $6.0-30.0$ & $0.193^{*}$ \\
Attitude toward smoking & $25.2 \pm 3.3$ & $12.0-30.0$ & $0.171^{*}$ \\
Parenting & $23.2 \pm 5.6$ & $6.0-30.0$ & $0.285^{*}$ \\
Intention & $27.1 \pm 4.5$ & $6.0-30.0$ & $0.616^{* *}$ \\
Smoking behavior & $27.6 \pm 4.9$ & $6.0-30.0$ & - \\
\hline${ }^{* *}$ p $<0.001 ;{ }^{*}$ p $<0.05$. & & &
\end{tabular}

Path analyses were used to determine the relationship between determinant factors and smoking behavior. The Chi-square was 95.02 and 
degree of freedom (df) was 9 , with a significant Chisquared test result $(p=0.09>0.05)$. The goodnessof-fit indices for the hypothesized model were RMSEA $=0.04, \mathrm{AGFI}=0.94, \mathrm{CFI}=0.95, \mathrm{NFI}=0.92$, and SRMR $=0.08$, indicated that the final model fit to the data. The final model obtained is presented in Figure 1. The final model accounted for $27 \%$ and $39 \%$ of the variance of intention and smoking behavior, respectively. The both direct and indirect, and total effects of the selected factors of smoking behavior are shown in Table 3.

Table 3: Summary of standardized direct, indirect, and total effects of independent variables toward smoking behavior

\begin{tabular}{|c|c|c|c|}
\hline \multirow[t]{2}{*}{ Variables on the final path model } & \multicolumn{3}{|c|}{ Smoking behavior } \\
\hline & Direct effect & Indirect effect & Total effect \\
\hline Environment & $0.015^{*}$ & $0.03^{*}$ & $0.34^{\star *}$ \\
\hline Culture & $-0.02^{*}$ & $0.02^{*}$ & $0.03^{*}$ \\
\hline Family function & $-0.05^{*}$ & $0.21^{*}$ & $0.16^{*}$ \\
\hline Skill to refuse & $0.30^{\star *}$ & $0.50^{\star \star *}$ & $0.36^{\star *}$ \\
\hline Subjective norm & $-0.22^{*}$ & $0.47^{\star}$ & $0.53^{\text {** }}$ \\
\hline Self-efficacy & $0.08^{*}$ & $0.07^{*}$ & $0.15^{*}$ \\
\hline Self-regulation & $0.07^{*}$ & $0.10^{*}$ & $0.16^{*}$ \\
\hline Attitude toward smoking & $0.06^{*}$ & $0.04^{*}$ & $0.11^{*}$ \\
\hline Parenting & $-0.04^{*}$ & $-0.03^{*}$ & $-0.07^{*}$ \\
\hline Intention & $0.37^{* *}$ & $0.44^{* *}$ & $0.61^{* *}$ \\
\hline
\end{tabular}

\section{Discussion}

According to this study, $28.6 \%$ of the adolescent ( aged 10 to 12 years olds) were current smokers and their aged of first smoking was 10.02 (SD=0.19). The majority of participants in the study were found to be less likely to smoke than previous research from Pakistan $(82.66 \%)$ [16]. In a study involving the elementary school in Turkey (7), 43\% of them reported having had smoking experience [17]. Smoking has become an emblem of mode throughout the new age of advanced growth [16]. Increasing current trends in smoking have appeared alarmingly in the younger population of the city. Teenagers are the most vulnerable to smoking either because of their individual character or as part of education, boarding and community relations [18]. Smoking is also harmful and leads to a variety of lethal diseases [19]. The government and law enforcement agencies should enforce the laws on smoking in schools, public transport, offices, and workplaces so that children could not get access to cigarette smoke. Teachers should discipline children against smoking to minimize the social evil.

The present study was intended to expand the TPB by including additional variables in its model: Smoking refusal skills, self-regulation, parenting, family function, environment, and culture. Although smoking cessation skills improved the predictive validity of the original TPB in terms of statistical significance, the findings of this study showed that this extended model was successful in predicting the intention to smoke more effectively than the original TPB. However, the previous study in Iran failed to predict the intention to smoke, including the ability to refuse smoking [20]. This study also found that the rate of smoking behavior is related to self-regulation. Self-regulation is a personality trait consisting of three aspects: Attention control, activation control, and inhibitory control [21]. This is consistent with earlier research that says that self-regulation is the second key knowledge structure that affects behavior change [22].

Self-efficacy has influenced the intention and behavior of smoking. In prior meta-analysis, the strongest predictor of intention is self-efficacy [23]. Self-efficacy is a psychological mediator of health

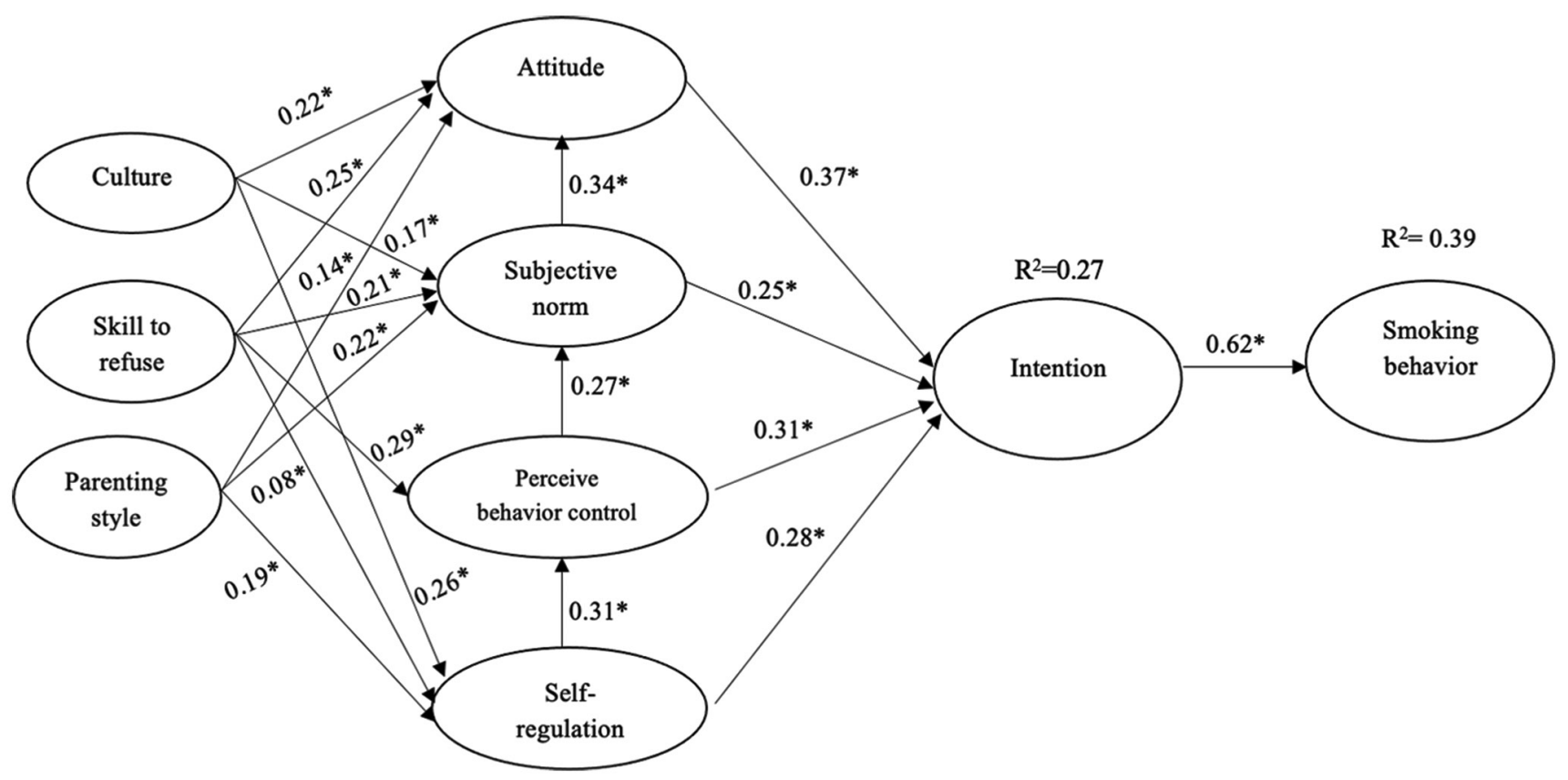

Figure 1: Path diagram of determinant smoking behavior among adolescent in Indonesia 
because it will lead one to practice disease prevention activities [24]. A person's self-efficacy is determined by their actions and experiences with their parents, their friends, and their teachers. A relationship with peers is extremely important in the development of adolescents. Not only does it influence the adolescent's own selfperceptions but it also influences the adolescent's perceptions of other people in the community and the way in which others treat the adolescent peer environments provide many different opportunities for peer learning and peer modeling. That is, positive peer relationships of encouragement, sympathy, mutual support, and acceptance may positively mediate the development in social conflicts through encouraging sources of individual independence, suggesting that such effects may be mediated by representative experiences [25].

Our study found that there is significant association between all five constructs of a TPB and smoking behavior. These results have shown that TPB is a highly successful predictor of smoking behavior. Perception of behavior control contributed more significantly to this prediction than attitudes and subjective norms. This was expected because of the role perception plays in behavioral control of lessvolitional behavior. The research findings are similar to previous studies [26], [27], [28]. Smoking literature shows that low perception of behavioral control is related to smoking initiation and smoking rate, as well as greater difficulty in stopping and/or higher rates of relapse among adolescents [20], [26]. In a similar study, Norman et al. also concluded that the TPB was predictive of intentions to quit smoking with perceived control as the most important predictor [20], [27]. Despite the fact that all the relationships were tested, the environmental impact is more significant than the personal one. This topic is interesting because there are environmental and personal constraints that may prevent real smoking cessation, such as an environmental barrier might be that everyone at school and a personal barrier might be nicotine dependence. It is worthwhile to explore the connection between determinants of smoking using different conceptualization and operationalization.

\section{Conclusion}

This finding provides an initial understanding of determinant of smoking using an extended of TPB among elementary students in Indonesia. This is one of the first studies to examine factors affecting smoking behavior, thus future research is needed to confirm our findings. This study also provides a significant contribute for clinical a practice and policy maker as a basic data to establish future intervention to promote no tobacco use among elementary student to achieve optimal well-being to prevent a fatal disease.

\section{Ethics Approval and Consent to Participate}

The study was approved by the International Review Board of the affiliated university (045/ $\mathrm{ETIK} / 2019$ ). As the information was also collected at the school, the Ministry of Health and Research and Development in West Java, Indonesia, also provided further clearance. Informed consent was obtained from the parent or the parent's legal guardian. Privacy and confidentiality were ensured throughout the study period by keeping all personal identifiers confidential.

\section{Availability of Data and Materials}

The data that support the findings of the current study are available from the corresponding author on request.

\section{Authors' Contributions}

ANH designed the study and recruited the participants. $\mathrm{ANH}, \mathrm{MN}$, and $\mathrm{AK}$ conducted data collection analyzed the data and wrote the manuscript. $\mathrm{ANH}, \mathrm{RM}, \mathrm{HR}$, and $\mathrm{AB}$ contributed to the design of the study and manuscript writing. All authors contributed, read, and approved the final manuscript.

\section{References}

1. World Health Organization. Tobacco: Key Facts. Geneva: World Health Organization; 2019. p. 1. Available from: https://www. who.int/news-room/fact-sheets/detail/tobacco. [Last accessed on 2019 Aug 20].

2. Kemenkes RI. Laporan Nasional Riskesdas 2018. Jakarta: Badan Penelitian dan Pengembangan Kesehatan; 2019

3. Tapera R, Mbongwe B, Mhaka-Mutepfa M, Lord A, Phaladze NA, Zetola NM. The theory of planned behavior as a behavior change model for tobacco control strategies among adolescents in Botswana. PLoS One. 2020;15(6):e0233462. https://doi. org/10.1371/journal.pone.0233462 PMid:32502211

4. Rodríguez $O$, Vázquez, R. Psychosocial risk factors for adolescent smoking: A school-based study. Int J Clin Health 
Psychol. 2011;11:23-33.

5. Rohmat R. Family and parenting patterns. Stud Gend Anak. 2010;5(1):35-46.

6. Szapocznik J, Prado G, Burlew AK, Williams RA, Santisteban DA. Drug abuse in African American and Hispanic adolescents: Culture, development, and behavior. Annu Rev Clin Psychol. 2007;3:77-105. https://doi.org/10.1146/annurev. clinpsy.3.022806.091408

PMid:17716049

7. Loke AY, Mak Y. Family process and peer influences on substance use by adolescents. Int J Environ Res Public Health. 2013;10(9):3868-85. https://doi.org/10.3390/ijerph10093868 PMid:23985772

8. Allem JP, Soto DW, Baezconde-Garbanati L, Sussman S, Unger JB. Cultural and social influences on adolescent smoking dissipate by emerging adulthood among Hispanics in Southern California. J Immigr Minor Health. 2015;17(1):192-7. https://doi. org/10.1007/s10903-013-9910-9

PMid:24057805

9. Seo DC, Huang Y. Systematic review of social network analysis in adolescent cigarette smoking behavior. J Sch Health. 2012;82(1):21-7. https://doi. org/10.1111/j.1746-1561.2011.00663.x

PMid:22142171

10. Ayubi E, Sani M, Safiri S, Morasae EK, Almasi-Hashiani A, Nazarzadeh M. Socioeconomic determinants of inequality in smoking stages: A distributive analysis on a sample of male high school students. Am J Mens Health. 2017;11(4):1162-8. https:// doi.org/10.1177/1557988315585822

PMid:26008735

11. van Loon AJ, Tijhuis M, Surtees PG, Ormel J. Determinants of smoking status: Cross-sectional data on smoking initiation and cessation. Eur J Public Health. 2005;15(3):256-61. https://doi. org/10.1093/eurpub/cki077

PMid:15923210

12. Elshatarat RA, Yacoub MI, Khraim FM, Saleh ZT, Afaneh TR. Self-efficacy in treating tobacco use: A review article. Proc Singapore Healthc. 2016;25(4):243-8. https://doi. org/10.1177/2010105816667137

13. Ajzen I. The theory of planned behavior. Organ Behav Hum Decis Process. 1991;5:179-211.

14. Symons $D$, Hausenblas $H$. The theories of reasoned action and planned behavior applied to exercise: A meta-analytic update. Phys Act Health. 2005;2:76-97. https://doi.org/10.1123/ jpah.2.1.76

15. Schermelleh-Engel $K$, Moosbrugger $H$, Müller $H$. Evaluating the fit of structural equation models: Tests of significance and descriptive goodness-of-fit measures. MPR Online. 2003;8:23-74.

16. Ejaz R, Salaria SM, Bukhari MH, Dar SA, Ahmed A, Ejaz U, et al. Rising trends of smoking in elementary students. Pak J Med Health Sci. 2015;9:48-50.

17. Suat $K$, Hikmet $C$, Nalbant A, Bilgin C. Smoking prevalence among elementary school-age children in Sirnak province in
Turkey. Biomed Res. 2017;28:5054-7.

18. Lakon CM, Hipp JR, Timberlake DS. The social context of adolescent smoking: A systems perspective. Am J Public Health. 2010;100(7):1218-28. https://doi.org/10.2105/ ajph.2009.167973

PMid:20466966

19. West R. Tobacco smoking: Health impact, prevalence, correlates and interventions. Psychol Health. 2017;32(8):1018-36. https:// doi.org/10.1080/08870446.2017.1325890

PMid:28553727

20. Karimy M, Zareban I, Araban M, Montazeri A. An extended theory of planned behavior (TPB) Used to predict smoking behavior among a sample of Iranian medical students. Int J High Risk Behav Addict. 2015;4(3):e24715. https://doi.org/10.5812/ ijhrba. 24715 PMid:26495261

21. Padin AC, Emery CF, Vasey M, Kiecolt-Glaser JK. Self-regulation and implicit attitudes toward physical activity influence exercise behavior. J Sport Exerc Psychol. 2017;39(4):237-48. https://doi. org/10.1123/jsep.2017-0056 PMid:28937320

22. Ryan, P. Integrated theory of health behavior change: Background and intervention development. Clin Nurse Spec. 2009;23(3):161-70; quiz 171-2. https://doi.org/10.1097/ nur.0b013e3181a42373 PMid:19395894

23. Vinothkumar M, Subramanian S. Self-efficacy, attitude and subjective norms as predictors of youth's intention to enlist in defence services. J Indian Acad Appl Psychol. 2016;42(2):310-9.

24. Wachs S, Görzig A, Wright MF, Schubarth W, Bilz L. Associations among adolescents' relationships with parents, peers, and teachers, self-efficacy, and willingness to intervene in bullying: A social cognitive approach. Int J Environ Res Public Health. 2020;17(2):420. https://doi.org/10.3390/ijerph17020420 PMid:31936333

25. Armum P, Chellappan K. Social and emotional self-efficacy of adolescents: Measured and analysed interdependencies within and across academic achievement level. Int J Adolesc Youth. 2016;21(3):279-88. https://doi.org/10.1080/02673843.2015.106 7894

26. Shi Y, Ehlers S, Warner DO. The theory of planned behavior as applied to preoperative smoking abstinence. PLoS One. 2014;9(7):e103064. https://doi.org/10.1371/journal.pone.0103064 PMid:25057969

27. Minnix JA, Blalock JA, Marani S, Prokhorov AV, Cinciripini PM. Self-efficacy mediates the effect of depression on smoking susceptibility in adolescents. Nicotine Tob Res. 2011;13(8):699705. https://doi.org/10.1093/ntr/ntr061 PMid:21482619

28. Norman $\mathrm{P}$, Conner M, Bell R. The theory of planned behavior and smoking cessation. Health Psychol. 1999;18(1):89-94. https://doi.org/10.1037/0278-6133.18.1.89

PMid:9925050 